\title{
Anatomical Structure of Large Flying-Fox Bat's (Pteropus vampyrus) Forelimb Skeleton
}

\author{
Itsnaini Fadhilah Sifa*, Laila Ainun Nisa, Widya Bahartin \\ Undergraduated Program, Departement of Biology Education, UIN Sunan Kalijaga \\ Jl. Marsda Adi Sucipto No. 1 Yogyakarta 55281 \\ Email*: itsnasifa@gmail.com
}

\begin{abstract}
Large Flying-fox (Pteropus vampyrus) is a fruit-eating bat that belongs to the Chiroptera order. Anatomical variations in various animals affected by different feed and behavior. The Large Flying-fox Bat is a flying mammal that undergoes morphological adaptation regarding its environment and behavior. The forelimb of bat adapt to flying properties. The aim of this research is to determine the anatomical structure of Pteropus vampyrus forelimb. To find out the anatomical structure, Pteropus vampyrus skinned with a knife and sandpaper until it appears the parts of muscles and bones. This species has forearm length of 145-220 mm and has a very high flying habit.
\end{abstract}

Keywords: large flying fox, anatomical structure, muscle, bones.

\section{INTRODUCTION}

Megachiroptera are differs from Microchiroptera by having a simple external ear with its edge forming an unbroken ring and by having a second finger that relatively independent of the third finger and which usually bears a small claw. They do not possess any noseleaf (often well-developed in the Microchiroptera) or tragus (a small structure inside the ear). The tail membrane usually narrow and the tail generally short or absent, although it is moderately long in Notopteris. Where a tail is present, it is not integral with the tail membrane (Mickleburgh et.al., 1992). All of the Megachiroptera consume fruits, flowers and/or flower products. The grinding teeth of most species are large and flat to allow them to chew fruit. Nectar and flower feeders have relatively lighter jaws and smaller teeth, and usually have narrow, elongated muzzles and long tongues to allow them to probe deep into flowers. The body weight of Pteropus vampyrus is about $800 \mathrm{~g}$ and can carry fruits over $200 \mathrm{~g}$ (van der Pijl, 1957; Marshall \& McWilliam, 1982). Pteropus vampyrus can travel about $50 \mathrm{~km}$ each night for foraging so that longdistance dispersal may sometimes occur (Mickleburgh et.al., 1992).

Old World fruit bats (family Pteropodidae) are a diverse group of non-echolocating bats that inhabit tropical regions in Africa, Asia, Australia, and many Pacific islands. Pteropus (Flying foxes) is the type and most species genus, including approximately 63 species, or about a third of the nearly 200 species in the family (Brisson, 1762; Simmons, 2005). IUCN (2008) listed as Near Threatened because this species is in significant decline (but at a rate of probably less than $30 \%$ over ten years or three generations) because it is being over- harvested for food over much of its range, and because of ongoing degradation of its primary forest habitat, making the species close to qualifying for Vulnerable under criterion A. To appreciate just how distinctive bats are, consider one of their trademark traits: wings. A few mammals, such as flying squirrels, can glide from tree to tree, thanks to a flap of skin that connects their front and hind limbs. And in fact, experts generally agree that bats probably evolved from an arboreal, gliding ancestor. But among mammals, bats alone are capable of powered flight, which is a much more complex affair than gliding. They owe this ability to the construction of their wings (Simmons, 2008).

\section{METHODS}

The research was conducted at the Zoology Laboratory of UIN Sunan Kalijaga in November 2019. The tools used in this study were knife, sandpaper and the material is one long-lasting wet species of Pteropus vampyrus. First, prepared one long-lasting wet species of Pteropus vampyrus. Forelimb sections were observed to obey the anatomical structure from the arm to the finger structure. Furthermore, to determine the anatomical structure, the specimen skinned carefully with a knife and sandpaper until it appears the parts of muscles and bones.

\section{RESULTS AND DISCUSSION}

Compared to similarly sized terrestrial mammals, the bones of a bat's forearm are long and curved, the radius is large relative to the ulna (with which it is often fused), and the digits are elongated as a supporting frame for the 
membranous wings. (Riskin et.al, 2005). It is likely our observations which the forelimb structured by humerus (fig. 4), radius, ulna (fig. 5), carpal (fig. 6), metacarpal, thumb and phalanges. The bones of a bat's wing consist of greatly elongated forearm and finger bones that support and spread the thin, elastic wing membranes. The membranes extend backward to encompass hind limbs that are quite a bit smaller than those of a terrestrial mammal of comparable body size. Many bats also have a tail membrane between their hind legs. A unique bone called the calcar projects from the bat's heel to support the trailing edge of this membrane. By moving their fingers, arms, legs and calcars, bats can maneuver their wings in innumerable ways, making them superb fliers (Simmons, 2008).

The humerus is shorter in size compared to the radius. Special characteristics that distinguish ulna with a radius that is of bone diameter and bone length. Ulna has a length of $3 / 4$ of a radius, besides that the bone structure is also more elastic (fig. 5). Carpal has an irregular structure (fig. 6). The special feature of Pteropus vampyrus's forearm that distinguishes it from other bats is the long thumb with the shape of a curved, dark nail. This is because its body size is larger when compared to other species of bat. This thumb serves to climb trees or move from one branch to another.

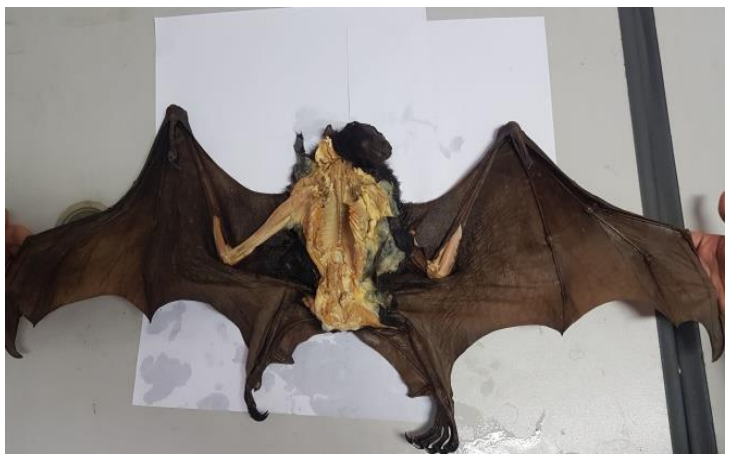

Figure 1. Morfology of Pteropus vampyrus

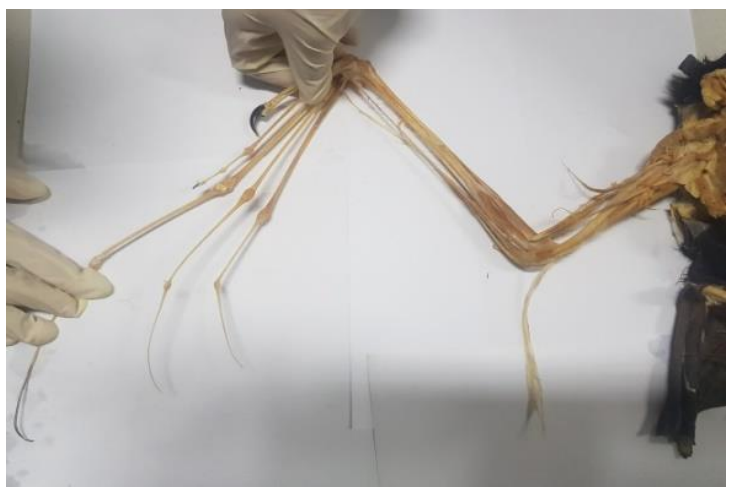

Figure 2. Forelimb Anatomy of Pteropus vampyrus

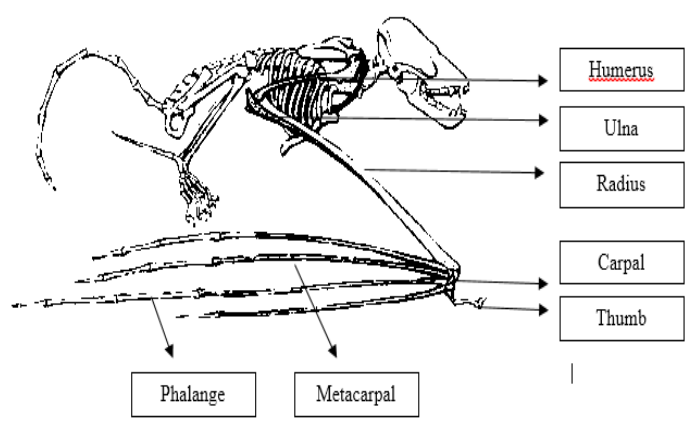

Figure 3. Skeleton of bat (Simmons, 2008)

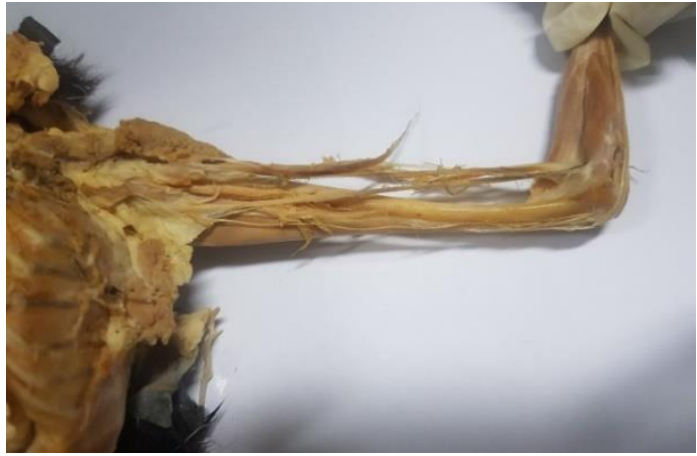

Figure 4. Humerus of Pteropus vampyrus.

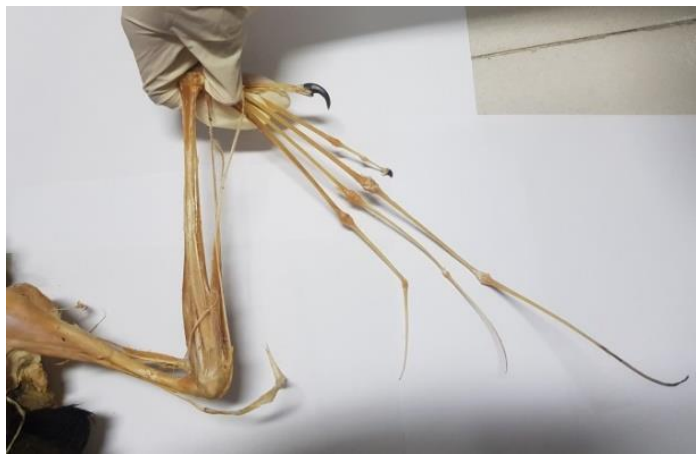

Figure 5. Radius and Ulna of Pteropus vampyrus.

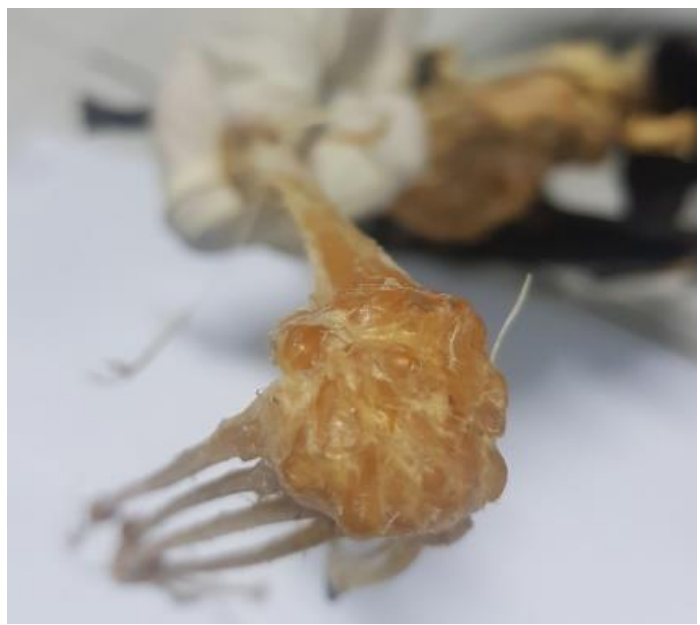

Figure 6. Metacarpal structure at Pteropus vampyrus 


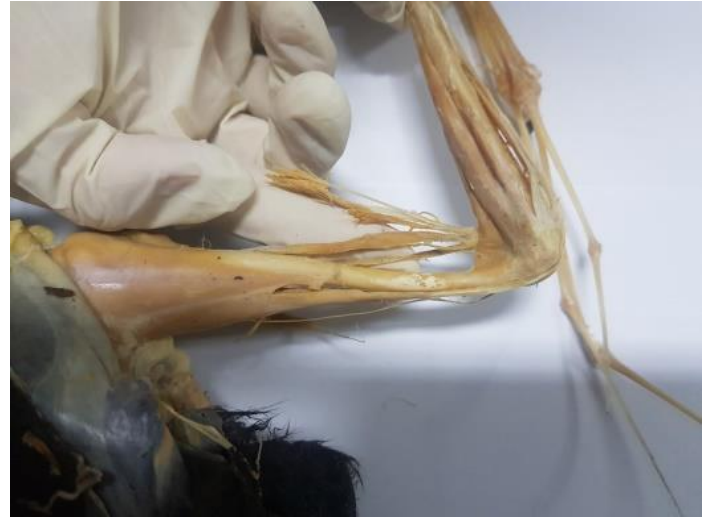

Figure 7. Anatomy structure of Pteropus vampyrus muscle and ligament

The wings of fruit bats have a well-developed but lightweight bone structure, robust muscles, and a tough patagium, or wing membrane. The rear legs are specially adapted to allow the bat to hang upside down without using any energy. Old World fruit bats utilize their thumbs, wings, and legs to climb, grab, and manipulate objects. They also use these appendages for thermoregulation, self-defense, and for supporting the weight of their young. Bats also have an unusual behavior in which they invert themselves by hanging from their thumbs to remain clean while defecating. Therefore, from an early age, the thumbs of Old World fruit bats must be strong enough to support their body weight (Seguin, et.al., 2000).

\section{CONCLUSION}

Based on the research that has been done, it can be concluded that the researcher can know the anatomical structure of the forearm on Pteropus vampyrus, which consists of the humerus, radius, ulna, carpal, metacarpal, and phalanges.

\section{REFERENCE}

IUCN. 2008. The IUCN Red List of Threatened Species: Pteropus vampyrus. http://dx.doi.org/10.2305/IUCN.UK.2008.RLTS.T18766A859 3657.en

Marshall, A.G., and McWilliam, A.N.. 1982. Ecological Observations on Epomophorine Fruit-bats (Megachiroptera) in West African Savanna Woodland. J. Zool., Lond. 198: 53-67

Mickleburgh, Simon. P., Hutson, Anthony M., and Racey, Paul A. 1992. Old World Fruit Bats: An Action Plan for their Conservation. Oxford: Information Press

Riskin, D. K., Bertram, J. E. A. and Hermanson, J. W. 2005. Testing The Hindlimb-Strength Hypothesis: Non-Aerial Locomotion By Chiroptera is Not Constrained by The Dimensions of The Femur or Tibia. J. Exp. Biol. 208: 13091319

Seguin, M., LeBlanc, D., Cruz, M., Rosenberg, A., Marsh, C., Poppeli, P., and Dampier, L. Reaching Out for Enrichment. The Shape of Enrichment 9 (4)

Simmons, N. B. 2008. Taking Wing. Scientific American. 299:6 (96-103)

Simmons, N.B., 2005. Order Chiroptera. In: Wilson, D.E., Reeder, D.M. (Eds.), Mammal Species of the World: A Taxonomic and Geographic Reference. Johns Hopkins University Press, Baltimore, MD, pp. 312-529

Van derPijl, L. 1957. The Dispersal of Plants by Bats (chiropterchory). Acta Bot. Neerl. 6: 291-315 
THIS PAGE INTENTIONALLY LEFT BLANK 